\title{
Influence of Microstructure and Temperature on the Interfacial Fracture Energy of Silicon Nitride/Boron Nitride Fibrous Monolithic Ceramics
}

\author{
Rodney W. Trice ${ }^{*}$, and John W. Halloran $^{*}$ \\ Materials Science and Engineering Department, University of Michigan, Ann Arbor, Michigan 48109-2136
}

\begin{abstract}
The microstructure and interfacial fracture energy of silicon nitride/boron nitride fibrous monoliths, $\Gamma_{\mathrm{BN}}$, were determined as a function of starting silicon nitride composition and temperature using the method described by Charalambides. The glassy phase created by the sintering aids added to the silicon nitride cells was shown to migrate into the boron nitride cell boundaries during hot-pressing. The amount of glassy phase in the boron nitride cell boundaries was shown to strongly influence $\Gamma_{\mathrm{BN}}$ at room temperature, increasing the fracture energy with increasing amounts of glass. Similar trends in the interfacial fracture energy as a function of temperature were demonstrated by both compositions of fibrous monoliths, with a large peak in $\Gamma_{B N}$ observed over a narrow temperature range. For silicon nitride cells densified with $6 \mathrm{wt} \%$ yttria and $2 \mathrm{wt} \%$ alumina, the room-temperature interfacial fracture energy was $37 \mathrm{~J} / \mathrm{m}^{2}$, remaining constant through $950^{\circ} \mathrm{C}$. A sharp increase in $\Gamma_{\mathrm{BN}}$, to $60 \mathrm{~J} / \mathrm{m}^{2}$, was observed between $1000^{\circ}$ and $1050^{\circ} \mathrm{C}$. This increase was attributed to interactions of the crack tip with the glassy phase in the boron nitride cell boundary. Measurements at $1075^{\circ} \mathrm{C}$ indicated a marked decrease in $\Gamma_{\mathrm{BN}}$ to $39 \mathrm{~J} / \mathrm{m}^{2}$. The interfacial fracture energy decreased with increasing temperature in the $1200^{\circ}$ to $1300^{\circ} \mathrm{C}$ regime, plateauing between 17 to $20 \mathrm{~J} / \mathrm{m}^{2}$. A crack propagation model based on linkup of existing microcracks and peeling/cleaving boron nitride has been proposed.
\end{abstract}

\section{Introduction}

$\mathrm{F}$ IBROUS monolithic ceramics have shown promise as a structural and tough ceramic material. ${ }^{1-5}$ Their ability to fail in a nonbrittle manner is accomplished by turning tensile initiated cracks in weak cell boundaries, creating surface area and absorbing energy in the process. As has been well documented, the ratio of the interfacial fracture energy of the two adjacent materials plays a key role in determining whether a crack propagating normal to the interface will be deflected. ${ }^{6,7}$ Thus, by choosing materials that exhibit fracture energies in the right proportion for crack deflection to occur, normally brittle materials can be made to fail in a nonbrittle manner. Clegg has demonstrated this concept experimentally, producing samples of alternating layers of $\mathrm{SiC}$ and graphite to achieve nonbrittle fracture of an all-ceramic system by weakening the interface. ${ }^{8-10}$ Other all-ceramic material systems are capable of achieving nonbrittle fracture as well. ${ }^{11}$ Fibrous monolithic ce-

\footnotetext{
F. W. Zok-contributing editor
}

\footnotetext{
Manuscript No. 190142. Received May 29, 1998; approved February 8, 1999. Based in part on the dissertation submitted by R. W. Trice for the Ph.D. degree in materials science and engineering, University of Michigan, Ann Arbor, Michigan, 1997.

Supported by DARPA/ONR (Contract No. N0014-95-0302).

${ }^{\star}$ Member, American Ceramic Society.

Now at Department of Materials Science and Engineering, Northwestern University, Evanston, Illinois 60208-0302.
}

ramics $^{12}$ are an extension of layered materials, and as such, are governed by the same rules regarding crack deflection. Consequently, the relative fracture energies of the two phases (in this case, silicon nitride and boron nitride) are very important.

Measurements of the interfacial fracture energy of layered $\mathrm{Si}_{3} \mathrm{~N}_{4} / \mathrm{BN}$ ceramics ${ }^{13}$ at room temperature indicate that $\Gamma_{\mathrm{BN}}$ is typically $40 \mathrm{~J} / \mathrm{m}^{2}$. To put this in perspective, crack growth along the monazite/alumina ${ }^{14}$ interface yields an interfacial fracture energy of $2.5 \mathrm{~J} / \mathrm{m}^{2}$. In SiC/graphite layered materials, ${ }^{10}$ the interfacial fracture energy is $7.5 \mathrm{~J} / \mathrm{m}^{2}$. It is known that hexagonal crystal structure $\mathrm{BN},{ }^{15}$ the type used in this study, does not sinter without the use of sintering aids. As no sintering aids were added to the BN cell boundary, it is perhaps surprising that the interfacial fracture energy is so high. As will be demonstrated in this paper, several microstructural features likely affect the fracture energy in $\mathrm{Si}_{3} \mathrm{~N}_{4} / \mathrm{BN}$ fibrous monoliths.

To date, very limited research has been performed to determine the interfacial fracture energy at elevated temperatures of these materials. This is due in part to early research focusing primarily on the $\mathrm{SiC} /$ graphite system, in which graphite forms the weak cell boundary. Graphite oxidizes between $500^{\circ}$ and $550^{\circ} \mathrm{C}$, prohibiting high-temperature testing unless an inert atmosphere is used. Boron nitride, the cell boundary material used presently, is fairly stable to $1000^{\circ} \mathrm{C}$, with short excursions to $1200^{\circ}$ to $1300^{\circ} \mathrm{C}$ possible without causing catastrophic oxidation. This paper addresses how both microstructural changes and temperature affect the interfacial fracture energy in silicon nitride/boron nitride fibrous monoliths. Fracture energy measurements, made using the Charalambides method, ${ }^{16}$ were performed between $25^{\circ}$ and $1300^{\circ} \mathrm{C}$. Microstructure was varied by adjusting the type and amount of sintering aids added to the silicon nitride cells.

\section{Experimental Procedure}

\section{(1) Fibrous Monolith Fabrication}

The basic building blocks of fibrous monoliths are smalldiameter filaments (approximately $250 \mu \mathrm{m}$ ) composed of a silicon nitride cell surrounded by a thin boron nitride cell boundary. Fibrous monoliths are made of hundreds of filaments, giving rise to their unique architecture. The fabrication methods for producing individual filaments have been described in detail elsewhere. ${ }^{2,5,12,17}$

The cell material of each filament was prepared from silicon nitride (SN-E-10, Ube Industries). Two different compositions of fibrous monoliths were fabricated for this study, varying the type and amount of sintering aid added to the silicon nitride. For the first composition, $6 \mathrm{wt} \% \mathrm{Y}_{2} \mathrm{O}_{3}$ (REaction, 99.9\% Pure, Johnson Matthey) and $2 \mathrm{wt} \% \mathrm{Al}_{2} \mathrm{O}_{3}$ (RC-HP DBM, Malakoff Industries) were added as sintering aids to the silicon nitride powder. In the second composition, only $4 \mathrm{wt} \% \quad \mathrm{Y}_{2} \mathrm{O}_{3}$ was used. The subsequent processing of each composition was identical except for the hot-pressing conditions.

Hexagonal boron nitride (Advanced Ceramics, HCP), consisting of platelike particles 7 to $10 \mu \mathrm{m}$ in diameter and 0.1 to $0.3 \mu \mathrm{m}$ thick, was used to fabricate the cell boundaries in the 
fibrous monoliths. The residual oxygen content was $0.4 \mathrm{wt} \%$. No sintering aids were added to the BN.

Filaments of each composition of silicon nitride with a BN shell were melt extruded. All filaments were manufactured by Advanced Ceramics Research in Tucson, AZ.

A filament winding approach, developed by King, ${ }^{18}$ was used to fabricate $\mathrm{Si}_{3} \mathrm{~N}_{4} / \mathrm{BN}$ fibrous monoliths with uniaxially aligned cells. The aligned green filaments were warm pressed at $150^{\circ} \mathrm{C}$ and 3 to $4 \mathrm{MPa}$, melting the polymer binder and slightly compacting them. The end result was an 8 to $9 \mathrm{~mm}$ thick "green" billet with unidirectionally aligned filaments displaying a high degree of order.

The polymer binder was removed from the green billets by heating to $700^{\circ} \mathrm{C}$ in flowing nitrogen. Residual carbon was removed in a post-binder burnout heat treatment to $400^{\circ} \mathrm{C}$ in flowing air. Testing following this additional processing step indicated that billets had less than $0.13 \mathrm{wt} \%$ residual carbon. Next, billets were loaded into a graphite die and hot-pressed for $2 \mathrm{~h}$ at $25 \mathrm{MPa}$. Fibrous monolithic billets fabricated with $6 \mathrm{wt} \%$ $\mathrm{Y}_{2} \mathrm{O}_{3}$ and $2 \mathrm{wt} \% \quad \mathrm{Al}_{2} \mathrm{O}_{3}$ sintering aids added to the silicon nitride cells were hot-pressed at $1740^{\circ} \mathrm{C}$ and designated as 6Y/2Al-FM. Billets fabricated with $4 \mathrm{wt} \% \mathrm{Y}_{2} \mathrm{O}_{3}$ were hotpressed at $1820^{\circ} \mathrm{C}$ and designated as $4 \mathrm{Y}-\mathrm{FM}$.

\section{(2) Specimen Fabrication and Testing}

The 4 to $4.5 \mathrm{~mm}$ thick sintered billets were machined to a thickness of $3 \mathrm{~mm}$ by removing equal amounts of material from both sides; $3 \mathrm{~mm} \times 4 \mathrm{~mm} \times 48 \mathrm{~mm}$ test bars were cut from these billets.

The density of each sample was measured using the immersion technique. ${ }^{19}$ The densities of $6 \mathrm{Y} / 2 \mathrm{Al}-\mathrm{FM}$ and $4 \mathrm{Y}-\mathrm{FM}$ samples were $3.07 \pm 0.01$ and $3.04 \pm 0.01 \mathrm{~g} / \mathrm{cm}^{3}$, respectively. The acoustic resonance ${ }^{20}$ method (J. W. Lemmons, Grindosonic) was used to determine the elastic modulus of the samples. The average moduli of $6 \mathrm{Y} / 2 \mathrm{Al}-\mathrm{FM}$ and $4 \mathrm{Y}-\mathrm{FM}$ samples were $287 \pm 1$ and $295 \pm 1 \mathrm{GPa}$, respectively. X-ray diffraction (XRD) of pulverized specimens indicated complete transformation of the starting $\alpha-\mathrm{Si}_{3} \mathrm{~N}_{4}$ powder to $\beta-\mathrm{Si}_{3} \mathrm{~N}_{4}$.

Testing was performed on a screw-driven load frame (Model 4483, Instron Corp., Canton, MA) equipped with a $5 \mathrm{kN}$ load cell and a deflectometer. Mechanical evaluations were made between $25^{\circ}$ and $1300^{\circ} \mathrm{C}$. Elevated temperature testing was performed using a clamshell furnace (Applied Test Systems, Butler, PA). A thermocouple, brought up through the bottom of the furnace, was placed within $5 \mathrm{~mm}$ of the sample, near the midspan, during testing. Prior to testing, the temperature was stabilized for $10 \mathrm{~min}$ within $2^{\circ} \mathrm{C}$ of the desired temperature. A silicon carbide fixture, with outer and inner spans fixed at 40 and $20 \mathrm{~mm}$, respectively, was used for all tests. All tests were conducted at a rate of $0.1 \mathrm{~mm} / \mathrm{min}$.

Interfacial fracture energy was obtained using the technique of Charalambides et al. ${ }^{16}$ The sample was initially notched and loaded in 3-point bending to extend the precrack into the boron nitride cell boundary, then carefully loaded into the 4-point fixture and tested at the desired temperature. Figure 1 shows a typical specimen response curve during the test. While the load-deflectometer curve shown is from a 6Y/2Al-FM tested at $1200^{\circ} \mathrm{C}$, this general response was observed at all temperatures. By measuring the steady-state load, $P_{\mathrm{SS}}$, and the heights of the cracked and uncracked beams, $h_{1}$ and $h_{2}$, respectively, the interfacial fracture energy, $\Gamma_{\mathrm{BN}}$, can be calculated from

$$
\Gamma_{\mathrm{BN}}=\frac{3 P_{\mathrm{ss}}^{2} a^{2}\left(1-v^{2}\right)}{2 E(T) b^{2}}\left[\frac{1}{h^{3}(1-n)^{3}}-\frac{1}{h^{3}}\right]
$$

where $a$ is the length of the moment arm $(10 \mathrm{~mm}), v$ is Poisson's ratio of the composite beam (approximately 0.27 ), $E(T)$ is the elastic modulus of the composite beam as a function of temperature, ${ }^{21} b$ is the width of the beam, $h$ is the total thickness of the beam, and $n$ is the height of the cracked beam $\left(h_{1}\right)$ divided by the total thickness of the beam. Three or more samples were tested at $25^{\circ}, 800^{\circ}$, and $1000^{\circ} \mathrm{C}$. Generally, only

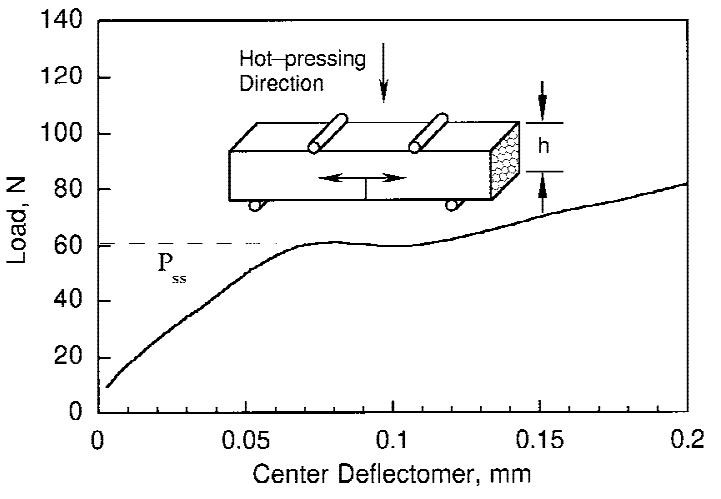

Fig. 1. Typical results from a Charalambides interfacial fracture energy test. These data were taken from a specimen tested at $1200^{\circ} \mathrm{C}$. The schematic shows the notched beam and the interfacial crack.

one sample was tested at the other temperatures. Cracked beam heights were measured in the steady-state load region and averaged. For each test, maximum and minimum values of $\Gamma_{B N}$ were calculated using the maximum and minimum cracked beam heights.

Electron microprobe analysis (EMPA) was used to precisely determine the composition of the cell boundary glassy phase. A Cameca MBX-MICROBEAM electron microprobe, equipped with two wavelength dispersive spectrometers, was operated at $10 \mathrm{kV}$ and $30 \mathrm{nA}$. Synthetic standards, including $\mathrm{Y}_{3} \mathrm{Al}_{5} \mathrm{O}_{12}$, 4-wt $\%$ - $\mathrm{Y}_{2} \mathrm{O}_{3}$-doped $\mathrm{Si}_{3} \mathrm{~N}_{4}$, and yttria-stabilized $\mathrm{ZrO}_{2}$, were used to calibrate for $\mathrm{N}, \mathrm{O}, \mathrm{Al}, \mathrm{Si}, \mathrm{Zr}$, and $\mathrm{Y}$. A point-beam was used to analyze volumes approximately 2 to $3 \mu \mathrm{m}$ in size. Based on counting statistics, the relative compositional errors associated with each element were typically $1 \%$ to $2 \%$.

\section{Results and Discussion}

\section{(1) Overview of Microstructure in BN Cell Boundaries}

Figure 2 presents a cross-sectional view of a typical 6Y/2AlFM. Multiple filaments, each consisting of a silicon nitride cell surrounded by a boron nitride cell boundary, form a unidirectionally aligned network of ceramic. Previous interfacial fracture energy testing has shown that the crack propagates in the boron nitride cell boundary ${ }^{13}$ rather that at the silicon nitride/ boron nitride interface. Thus, BN cell boundary microstructure will likely control the interfacial fracture energy.

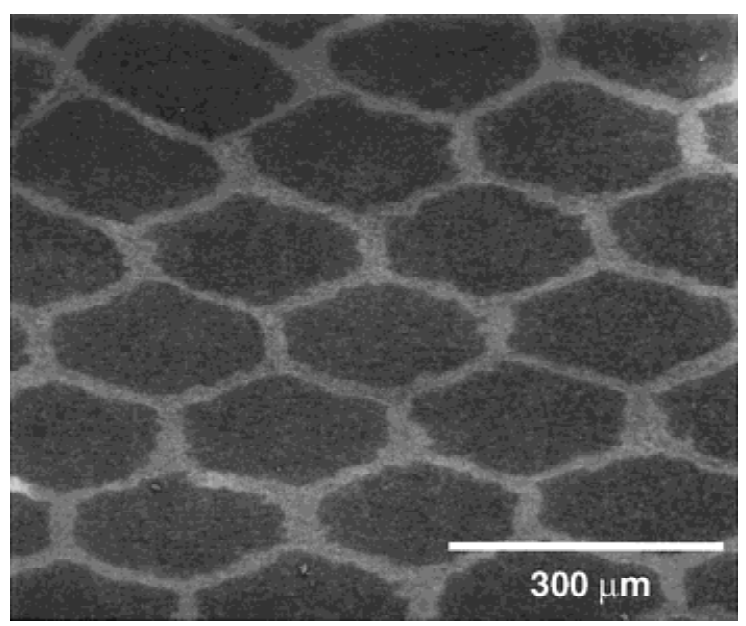

Fig. 2. SEM micrograph showing a typical cross-sectional view of a unidirectional fibrous monolith. The dark phase is silicon nitride and the lighter phase is boron nitride. 
(A) Sintering Aid Migration into the BN Cell Boundary: For sintering of $\mathrm{BN}$ to occur, an appreciable amount of oxygen must be incorporated into its crystal structure. ${ }^{22}$ As the powders used to fabricate cell boundaries in fibrous monoliths have very low oxygen contents, sintering of these powders is not expected. This condition was confirmed by showing that hot-pressed BN powders $\left(1740^{\circ} \mathrm{C}\right.$ and $\left.25 \mathrm{MPa}\right)$ demonstrated no structural integrity. However, similarly hot-pressed $\mathrm{Si}_{3} \mathrm{~N}_{4} / \mathrm{BN}$ fibrous monoliths are strong, demonstrating flexure strengths between 500 and $600 \mathrm{MPa} .{ }^{12}$

Polished cross sections of fibrous monoliths indicated the presence of an additional phase in the cell boundary. A typical example in a 6Y/2Al-FM is shown in Fig. 3. Apparent in the image is a bright phase, clustered in the cell boundaries. As a reminder, no sintering aids were added to the boron nitride during processing. This phase was determined to be amorphous ${ }^{12}$ using selected area diffraction techniques.

Using electron microprobe analysis, the composition of the cell boundary glassy phase in $6 \mathrm{Y} / 2 \mathrm{Al}-\mathrm{FM}$ was determined to be approximately $\mathrm{Si}_{0.18} \mathrm{Y}_{0.13} \mathrm{Al}_{0.05} \mathrm{Zr}_{0.02} \mathrm{~N}_{0.08} \mathrm{O}_{0.55}$, with the zirconium resulting from milling media contamination. The presence of yttrium and aluminum strongly suggests that the sintering aids used in the processing of the silicon nitride cells are migrating into the boron nitride cell boundary during hotpressing.

The volume percent of glassy phase in the regions where three cells meet (triple junctions) and where two cells meet (double junctions) was measured using the point-fraction method. These regions are schematically represented in Fig. 4. Less glassy phase was present in double junctions, $14 \pm 2.0$ vol\%, than in triple junctions, $24.8 \pm 2.0$ vol\%. It is believed that the glassy phase flows into voids of the cell boundary created by misaligned boron nitride platelets during hotpressing. The increased amount of misalignment associated with the boron nitride platelets in triple junction regions would lead to an increased amount of voids into which glassy phase could flow.

As the sintering aid is created and migrates into the void region within the cell boundary, less glass is available for densification. Doche and Thevenot ${ }^{23}$ witnessed this phenomenon in the fabrication of a similar composition of silicon nitride with boron nitride additions. In their study, porosity increased with increasing BN additions for a constant hot-pressing temperature. In the present study, we also observed that it was generally more difficult to densify a fibrous monolith than monolithic silicon nitride. As a result, fibrous monoliths with 15 to 20 vol\% additions of boron nitride are hot-pressed at temperatures approximately $20^{\circ} \mathrm{C}$ higher than required to

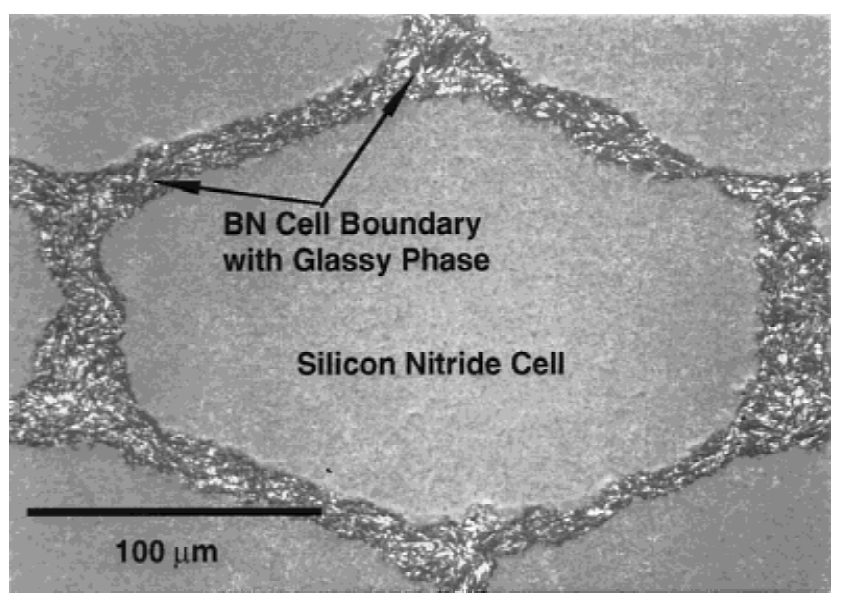

Fig. 3. Low-magnification backscattered image of a typical cell boundary in a $6 \mathrm{Y} / 2 \mathrm{Al}-\mathrm{FM}$. The brighter phase in the cell boundary is the glassy phase.
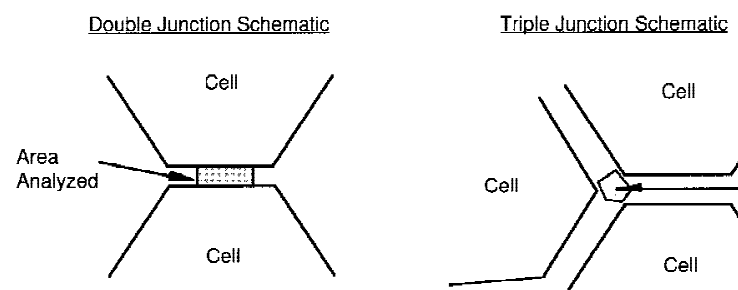

Fig. 4. Schematics of BN cell boundary regions where the volume percent of glass was measured.

densify monolithic ceramics of the same silicon nitride composition.

(B) Microcracking in Boron Nitride: An example of microcracking in boron nitride is shown in Fig. 5, a highresolution TEM image with the [0001] direction noted. The micrograph shows stacked basal planes of boron nitride, viewed edge-on. It is clear that splitting between the basal planes of the boron nitride has occurred, with separation between basal planes favored due to the weak van der Waals bonding in the [0001] direction. ${ }^{12,24-27}$ Graphite, with a structure similar to that of hexagonal $\mathrm{BN}$, has a similar cracked structure, initially observed by Mrozowski, ${ }^{28}$ and then by others. ${ }^{29,30}$

Close examination reveals that the fractured platelet is connected by a thin strand of boron nitride, called a ligament. It is clear from the image that the ligament is continuous from one side of the boron nitride platelet to the other. The direction normal to these strands within the plane of the page has previously been shown to be of [0001] orientation. ${ }^{27}$

The origin of microcracks in boron nitride has been attributed to thermal stresses that arise during cooling from the processing temperature to room temperature. ${ }^{12,27,31}$ Besides thermally generated microcracking, the loads generated during hot-pressing, along with the growth of stiff silicon nitride grains into the more compliant boron nitride, could apply large tensile and/or shear stresses and cause microcrack formation. ${ }^{27,32}$

\section{(2) Effect of Volume Percent Cell Boundary Glassy Phase on $\Gamma_{B N}$ at Room Temperature}

Figure 6 shows how differences in the amount of glassy phase in the cell boundary affect $\Gamma_{\mathrm{BN}}$ at $25^{\circ} \mathrm{C}$. A linear relationship is observed between the interfacial fracture energy and the percentage of glassy phase in the boron nitride boundary. For 6Y/2Al-FM, hot-pressed at $25 \mathrm{MPa}$, the interfacial fracture energy was $37 \mathrm{~J} / \mathrm{m}^{2}$ with $19 \mathrm{vol} \%$ glass present. For a $6 \mathrm{Y} / 2 \mathrm{Al}-$ FM hot-pressed between 15 and $20 \mathrm{MPa}, \Gamma_{\mathrm{BN}}$ drops to $22 \mathrm{~J} / \mathrm{m}^{2}$ (with only $16 \mathrm{vol} \%$ glass present). As a result of lowering the processing pressure, it is believed that less glassy phase was

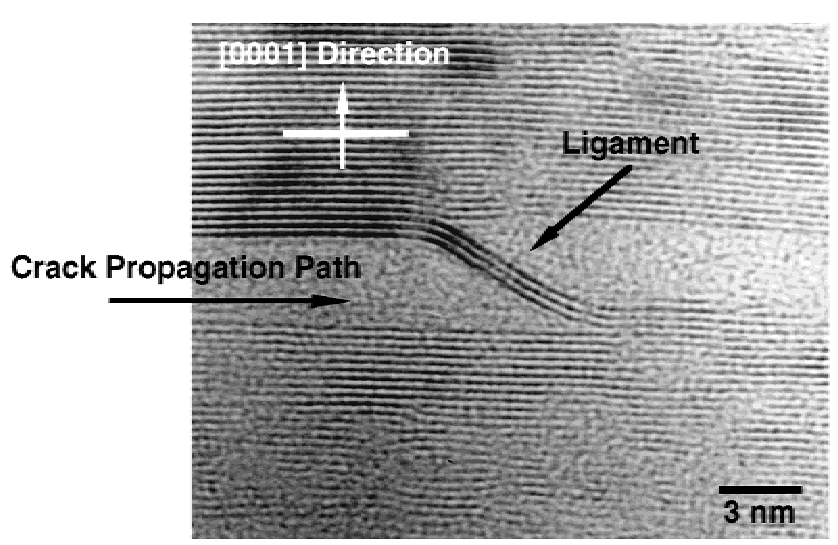

Fig. 5. High-resolution image of a cracked boron nitride platelet connected by a ligament. Micrograph courtesy of Eric Wang. 


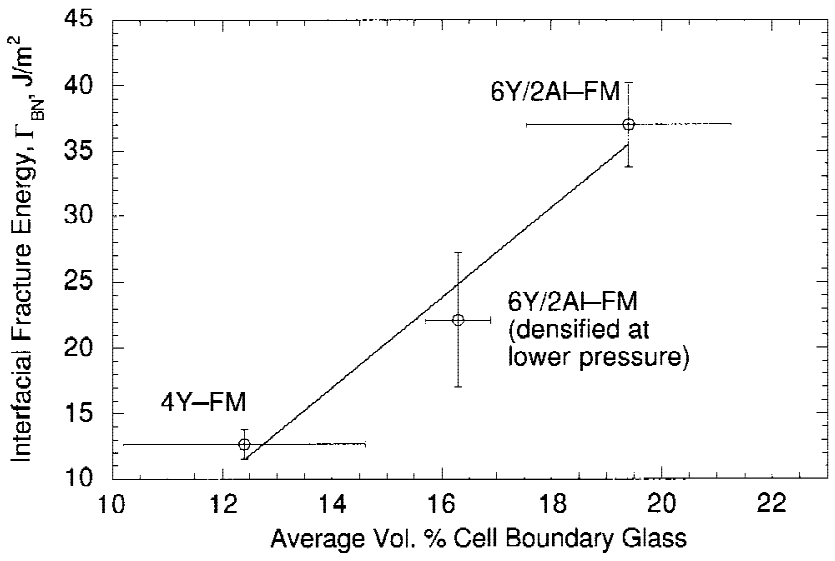

Fig. 6. Role of cell boundary glassy phase on the interfacial fracture energy at room temperature.

forced into the boron nitride cell boundary during processing. From Fig. 6 it is also evident that extrapolation of the data to 0 vol\% cell boundary glassy phase indicates that little or no energy would be required to separate adjacent BN grains. Thus, the glassy phase seems to act like glue, adhering the boron nitride grains to one another.

Besides hot-pressing pressure, the amount of glassy phase available to flow into the cell boundaries also influences $\Gamma_{\mathrm{BN}}$. If we assume that approximately $3 \mathrm{wt} \%$ silica exists on the surface of the silicon nitride ${ }^{33}$ and that it combines with the 4 wt $\%$ yttria to form the glassy phase, approximately 7 vol\% glass is created during hot-pressing 4Y-FMs. Some of this stays in the cells and resides as a thin, amorphous layer between the silicon nitride grains while some of the glass migrates to the boron nitride cell boundary. From a similar calculation and assumptions, the $6 \mathrm{Y} / 2 \mathrm{Al}-\mathrm{FM}$ creates approximately $10 \mathrm{vol} \%$ glass. Thus, more glassy phase is available in the $6 \mathrm{Y} /$ 2Al-FM system to flow into the cell boundary. Microstructural investigations revealed that 19 and $13 \mathrm{vol} \%$ of cell boundary glassy phase was present in 6Y/2Al-FM and 4Y-FM, respectively. This volume difference resulted in a $200 \%$ increase in $\Gamma_{B N}$ for the 6Y/2Al-FM.

\section{(3) Temperature Effects on the Interfacial Fracture Energy}

The interfacial fracture energy of boron nitride, $\Gamma_{\mathrm{BN}}$, as a function of temperature for 6Y/2Al-FMs is presented in Fig. 7. The room-temperature interfacial fracture energy of boron nitride was determined to be about $40 \mathrm{~J} / \mathrm{m}^{2}$. The interfacial fracture energy of the boron nitride remained essentially constant up to $950^{\circ} \mathrm{C}$, before rapidly increasing to $60 \mathrm{~J} / \mathrm{m}^{2}$ between $1000^{\circ}$ and $1050^{\circ} \mathrm{C}$. $\Gamma_{\mathrm{BN}}$ decreased again to $40 \mathrm{~J} / \mathrm{m}^{2}$ for samples tested at $1075^{\circ}$ and $1100^{\circ} \mathrm{C}$. $\Gamma_{\mathrm{BN}}$ decreased further with increasing temperature before plateauing at about $20 \mathrm{~J} / \mathrm{m}^{2}$ in the $1200^{\circ}$ to $1300^{\circ} \mathrm{C}$ temperature regime.

The $\Gamma_{\mathrm{BN}}$ results for 4Y-FM are also presented in Fig. 7. Only limited interfacial fracture experiments were performed on this composition. The interfacial fracture energy measured between room temperature and $1000^{\circ} \mathrm{C}$ ranged between 12 and $16 \mathrm{~J} / \mathrm{m}^{2}$, while at $1100^{\circ} \mathrm{C}, \Gamma_{\mathrm{BN}}$ was about $40 \mathrm{~J} / \mathrm{m}^{2}$. The fracture energy decreased to $10 \mathrm{~J} / \mathrm{m}^{2}$ at $1200^{\circ} \mathrm{C}$.

Similar behavior was noted in comparing the interfacial fracture energies of 6Y/2Al-FM and 4Y-FM. First, both were characterized by a region in which $\Gamma_{\mathrm{BN}}$ was virtually constant with temperature. Second, both compositions exhibited a narrow peak in $\Gamma_{\mathrm{BN}}$. The $\Gamma_{\mathrm{BN}}$ increase observed near $1000-1050^{\circ} \mathrm{C}$ in $6 \mathrm{Y} / 2 \mathrm{Al}-\mathrm{FM}$ was shifted $50-100^{\circ} \mathrm{C}$ to $1100^{\circ} \mathrm{C}$ in $4 \mathrm{Y}-\mathrm{FM}$. Third, the narrow peak in interfacial fracture energy was followed by a dramatic drop in $\Gamma_{\mathrm{BN}}$. The following discussion will be organized into the three characteristic regions observed in the $\Gamma_{\mathrm{BN}}$ vs temperature plots.

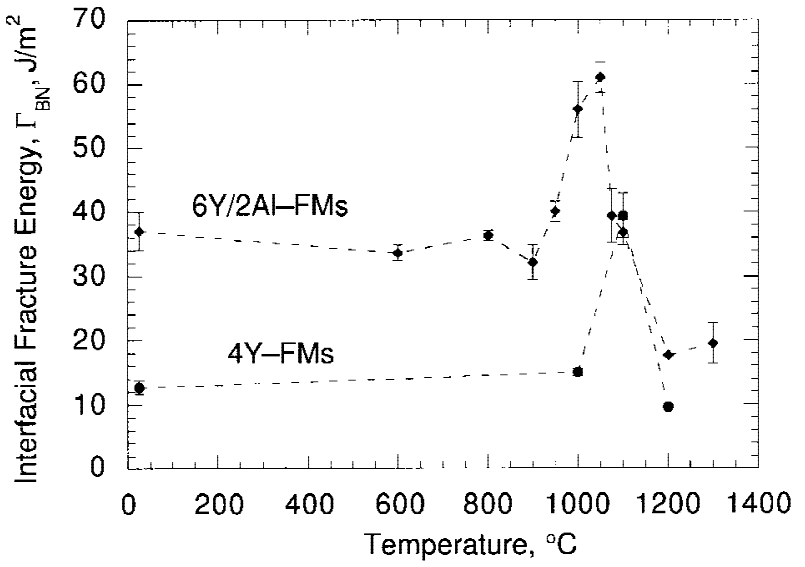

Fig. 7. Plot of $\Gamma_{\mathrm{BN}}$ for both compositions of fibrous monoliths studied. 6Y/2Al-FMs exhibited a sharp increase in $\Gamma_{\mathrm{BN}}$ between $1000^{\circ}$ and $1050^{\circ} \mathrm{C}$. The interfacial fracture energy peak in $4 \mathrm{Y}$-FMs was shifted to $1100^{\circ} \mathrm{C}$.

(A) Constant $\Gamma_{B N}$ Region: As shown in Fig. 7, no change in the fracture energy of the boron nitride cell boundary is observed below $950^{\circ}$ and $1000^{\circ} \mathrm{C}$ in $6 \mathrm{Y} / 2 \mathrm{Al}-\mathrm{FMs}$ and $4 \mathrm{Y}$-FMs, respectively. All data generated within this region for both fibrous monolith compositions fall within the experimental error. As previously stated, boron nitride itself provides no resistance to fracture, but rather, its strength is controlled by the presence of the glassy phase. Thus, the likely reason no changes are observed in the interfacial fracture energy over this broad temperature regime is that the glassy phase has not reached sufficient temperature to soften.

Insight into the accompanying crack growth mechanism can be gained by considering Fig. 5. The lowest energy fracture path for a propagating crack would likely be to link up existing microcracks rather than to cleave uncracked platelets of boron nitride or fracture regions of glassy phase. However, the linking of microcracks can occur only by breaking numerous $\mathrm{BN}$ ligaments.

During testing, the crack tip experiences roughly equal opening and shearing stress intensities. Therefore, increasing loads will tend to rotate the split $\mathrm{BN}$ grain about the ligament. Ultimately, the applied load will peel or cleave a fragment of the boron nitride platelet from the top or bottom surface. Cleaving of boron nitride in this orientation is favored over fracturing the ligament due to bonding differences associated with crystal orientation. Based on this model of crack propagation, a threedimensional representation of the two matching failure surfaces is shown in Fig. 8. One surface is characterized by a peeled boron nitride fragment extending above the boron nitride surface. The other failure surface is characterized by a step where the peeled boron nitride fragment is ripped up through several atomic layers during the failure process. With these schematics in mind, consider Fig. 9, SEM micrographs of an interfacial fracture energy specimen tested at $25^{\circ} \mathrm{C}$. Both peeled boron nitride platelets and stepped surfaces are observed.

(B) $\Gamma_{B N}$ Peak Region: As discussed, a sharp increase in $\Gamma_{\mathrm{BN}}$ was observed over the narrow temperature range of $1000^{\circ}$ to $1050^{\circ} \mathrm{C}$ for $6 \mathrm{Y} / 2 \mathrm{Al}-\mathrm{FMs}$ and near $1100^{\circ} \mathrm{C}$ for $4 \mathrm{Y}-\mathrm{FMs}$. As shown previously, ${ }^{12}$ the path of the deflected and delaminating crack has been shown to propagate within the cell boundary between grains of boron nitride rather than at the silicon nitride-to-boron nitride interface. Therefore, the changes in the interfacial fracture energy as the temperature is increased likely reflect changes in the physical properties of either the boron nitride or the cell boundary glassy phase.

(i) Boron Nitride Considerations: A potential explanation for the large peak in $\Gamma_{\mathrm{BN}}$ centers around mechanical property changes in the boron nitride. Close inspection of Fig. 5 reveals that a notch is created between the ligament and the cracked 


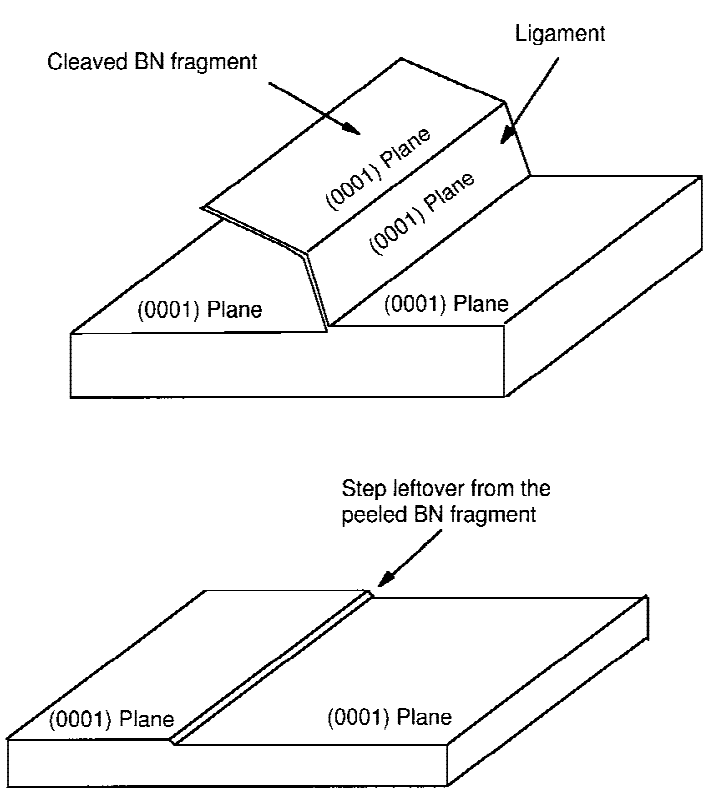

Fig. 8. Three-dimensional schematic of a single boron nitride grain that has failed as a result of both an opening and shear stress applied to the two cracked halves of a $\mathrm{BN}$ grain.

half of the BN platelet. It was previously argued that for crack propagation to occur these ligaments had to be broken by a cleaving/peeling process. If, upon increasing temperature, the sensitivity of this notch to crack propagation is decreased, perhaps due to increased plasticity in the boron nitride, an increase in $\Gamma_{\mathrm{BN}}$ would likely be noted.

Based on this premise, it might be expected that changes in the properties of the boron nitride would be reflected in the failure surface. Figures 9(a) and 10(a) compare the fracture surfaces of a $6 \mathrm{Y} / 2 \mathrm{Al}-\mathrm{FM}$ tested at $25^{\circ}$ and $1000^{\circ} \mathrm{C}$. There was no discernible difference between the fracture surfaces despite the large difference in the measured values of $\Gamma_{\mathrm{BN}}$. Furthermore, if changes in the properties of $\mathrm{BN}$ were responsible for the observed behavior, then the $\Gamma_{\mathrm{BN}}$ peak should occur at identical temperatures for both fibrous monoliths compositions because the same boron nitride starting powder was used in their fabrication. However, as shown in Fig. 7, there is a $50^{\circ}$ to $100^{\circ} \mathrm{C}$ difference in the $\Gamma_{\mathrm{BN}}$ peak for the two fibrous monolith compositions. This suggests that changes in the mechanical properties of the boron nitride are not responsible for the observed peaks in $\Gamma_{\mathrm{BN}}$.

(ii) Cell Boundary Glassy Phase Considerations: Having dismissed the possibility that the boron nitride is causing the peak in $\Gamma_{\mathrm{BN}}$ measurements, the focus will now be on the cell boundary glassy phase. It is well understood that interactions of a crack tip with a glassy phase can have a toughening affect. ${ }^{34}$ This effect is often a result of either crack tip blunting, in which the glassy phase decreases the sharpness of the propagating crack, or ductile ligament bridging, in which the glassy phase bridges the crack wake. For example, crack tip blunting was observed in $95 \%$ pure alumina samples, where a similar peak in the fracture energy was measured with increasing temperature. ${ }^{35}$ This increase was attributed to softening of a residual glassy phase that existed between the grains of alumina.

If this toughening mechanism is valid for fibrous monoliths, then the cell boundary glassy phase must be softened at the temperature of the $\Gamma_{\mathrm{BN}}$ peak. Published values for yttria/ alumina-doped silicon nitride indicate a $T_{\mathrm{g}}$ for the glassy phase between $950^{\circ}$ and $970^{\circ} \mathrm{C} .{ }^{36}$ The $T_{\mathrm{g}}$ of the glassy phase created during the processing of yttria-doped silicon nitride was determined to be $1000^{\circ}$ to $1020^{\circ} \mathrm{C} .{ }^{37}$ Thus, the $T_{\mathrm{g}}$ differences correspond with the observed $\Gamma_{\mathrm{BN}}$ shift observed between the two fibrous monolith compositions.
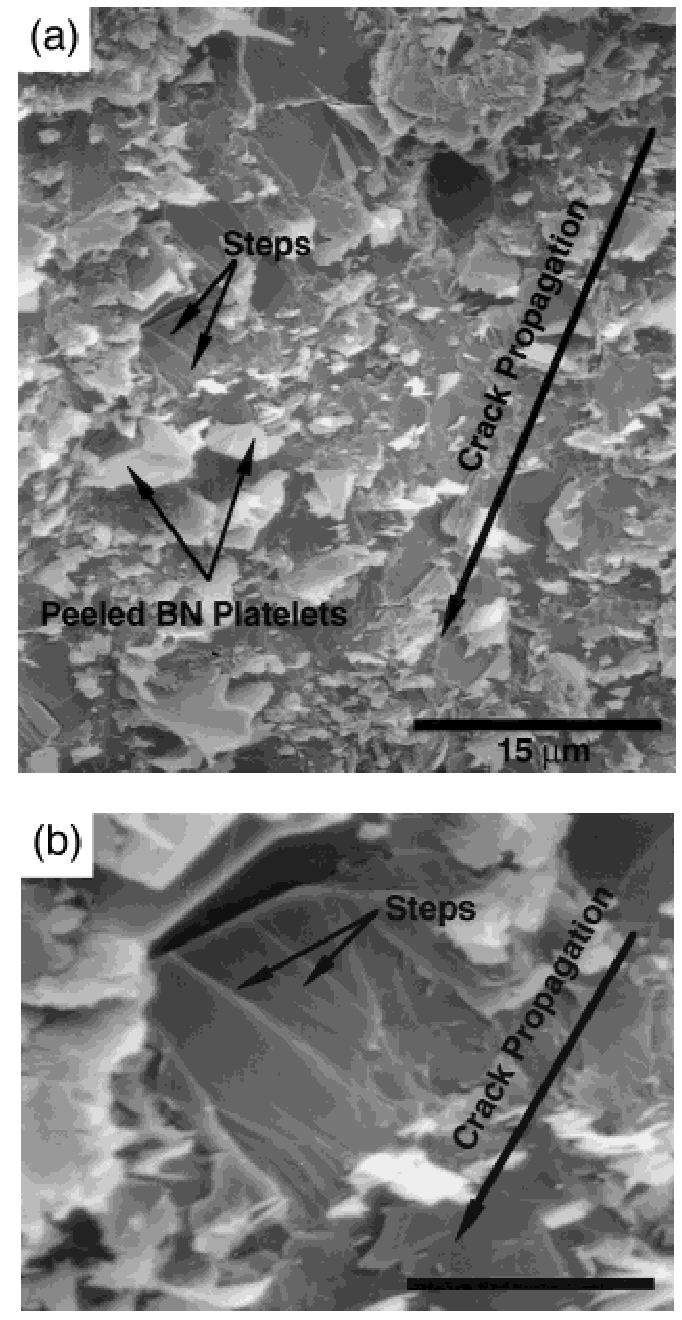

Figure 11 shows the failure surface of a 6Y/2Al-FM sample tested at $1000^{\circ} \mathrm{C}$. The micrograph was taken in the backscattered imaging mode, with the brighter phase representing the cell boundary glassy phase. Inspection of the fracture surface clearly indicates that the cell boundary glassy phase is cut by the propagating crack. Approximately 5 vol\% glass is found on this surface. Thus, the observed increase in the interfacial fracture energy may be the result of interactions of the crack tip with the cell boundary glassy phase. This mechanism is strongly supported by the fact that a shift in the $\Gamma_{\mathrm{BN}}$ peak is observed as the glass transition temperature of the glass is increased.

(C) Decreasing $\Gamma_{B N}$ Behavior: As shown in Fig. 7, a reduction in the interfacial fracture resistance of the boron nitride was observed between $1100^{\circ}$ and $1300^{\circ} \mathrm{C}$ for $6 \mathrm{Y} / 2 \mathrm{Al}-\mathrm{FMs}$ and at $1200^{\circ} \mathrm{C}$ in $4 \mathrm{Y}$-FMs. A similar decrease in $\Gamma_{\mathrm{BN}}$ following a large peak has been observed previously and related to a substantial decrease in the flow resistance of a glassy phase. ${ }^{38}$

A change in the fracture surface was also noted in this temperature regime. As temperature increased, the distance required to peel or cleave the BN ligaments such that they were completely removed from the platelet decreased. As proof of this, consider Figs. 9(a) and 10(b), failure surfaces of specimens tested at $25^{\circ}$ and $1300^{\circ} \mathrm{C}$, respectively. There are fewer of the large, peeled $\mathrm{BN}$ segments in the sample tested at $1300^{\circ} \mathrm{C}$ compared to the sample tested at $25^{\circ} \mathrm{C}$. The range of fragment lengths observed at both $25^{\circ}$ and $1300^{\circ} \mathrm{C}$ were esti- 